\title{
The distribution of carnitine and acetylcarnitine in the epididymis and epididymal spermatozoa of the boar
}

\author{
C. Jeulin*, J. C. Soufir†, J. Marson*, M. Paquignon $\ddagger$ and J. L. Dacheux $\ddagger$ \\ *Laboratoire d'Histologie-Embryologie and $\dagger$ Laboratoire de Biologie Cellulaire, C.H.U., 94275 Le \\ Kremlin Bicêtre, France; and $\ddagger$ Station de Physiologie de la Reproduction, I.N.R.A., 37380 Nouzilly, \\ France
}

\begin{abstract}
Summary. In the epididymal fluid of boars, the concentration of carnitine $(\mathrm{nmol} / \mathrm{mg}$ protein) began to increase from 20 in the distal caput, then rose progressively to 700 in the distal cauda. By contrast, the carnitine content of spermatozoa only started to increase in the proximal cauda where the concentration of carnitine in the fluid was $200-300 \mathrm{nmol} / \mathrm{mg}$ protein then gradually increased in spermatozoa from more distal sites. The increase in the acetylcarnitine content of spermatozoa paralleled that of the carnitine amount and represented $50 \%$ of the total carnitine (carnitine + acetylcarnitine). We conclude that the acetylcarnitine content of epididymal spermatozoa may be used as a marker of maturation.
\end{abstract}

\section{Introduction}

Carnitine is present in the epididymis at higher concentrations than in other body tissues in the rat (Marquis \& Fritz, 1965b) and other mammals (Casillas, 1972; see Brooks, 1980). Carnitine accumulates in spermatozoa as they mature in the epididymis as shown in the rat, bull, monkey, boar (Casillas, 1972, 1973), rabbit (Casillas \& Chaipayungpan, 1979), ram (Inskeep \& Hammerstedt, 1982) and hamster (Casillas et al., 1984). In-vitro studies have revealed that carnitine is rapidly acetylated when bovine epididymal spermatozoa are incubated with physiological substrates (Casillas \& Erickson, 1975), whereas long-chain acylcarnitine is not detectable (Casillas, 1973; Brooks et al., 1974; Van Dop et al., 1977). In vitro, acetylcarnitine serves as a readily accessible energy store which can be used when there is a great demand for energy in bovine epididymal spermatozoa (Milkowski et al., 1976).

The region of the epididymis where the concentration of carnitine first increases is the distal caput in the rat, the distal corpus in the boar and the ram (Hinton et al., 1979) and the proximal cauda in the rabbit and the hamster (Hinton et al., 1979; Casillas \& Chaipayungpan, 1979; Casillas et al., 1984). After the first rise, the carnitine concentration shows only slight gradual increase along the epididymis in the hamster, rabbit and boar (Hinton et al., 1979), but a 3-fold increase has been found in the rat (Hinton et al., 1979), and an 8-fold increase in the ram (Besançon et al., 1985). The origin of acetylcarnitine in the epididymal fluid is unclear. In epididymal fluid from the rabbit and the hamster, the concentration of acetylcarnitine increases 10 -fold or 50 -fold respectively between the corpus and cauda epididymidis (Casillas \& Chaipayungpan, 1979; Casillas et al., 1984). Casillas et al. (1984) found no clear increase in the intracellular concentration of acetylcarnitine in epididymal spermatozoa as they mature in the hamster, but Inskeep \& Hammerstedt (1982) found that the acetylcarnitine content $\left(\mu \mathrm{mol} / 10^{8}\right.$ spermatozoa) of ram spermatozoa increased from 13 in the caput to 320 in the cauda. The percentage of the total carnitine content of spermatozoa which is acetylated is 30 in the hamster (Casillas et al., 1984), 80 in the human (Brooks, 1979) and 85 in the ram (Inskeep \& Hammerstedt, 1982). In man, the acetylcarnitine in seminal plasma does not 
originate from the epididymis and is not produced in semen by sperm metabolism (Soufir \& Jeulin, 1985).

In the present study, we have examined the distribution of carnitine and acetylcarnitine in boar epididymal spermatozoa and fluid removed from various regions of the epididymis.

\section{Materials and Methods}

\section{Preparation of epididymal and rete testis fluid samples}

Epididymal fluid was collected from 9 regions of 6 epididymides from Large White boars aged 180 days according to the micropuncture technique described by Dacheux (1980). In brief, each region (Fig. 1 and Table 1 ) was flushed with $0.2 \mathrm{ml}$ Krebs-Ringer-bicarbonate solution (KRB) (Imai et al., 1979) saturated with $5 \% \mathrm{CO}_{2}$ in oxygen (pH 7.4), except region 9 which was perfused without dilution using paraffin oil. The samples were then centrifuged at $10000 \mathrm{~g}$ for $10 \mathrm{~min}$ and the supernatants stored at $-20^{\circ} \mathrm{C}$. The rete testis fluid from 2 boars was collected by catheterization (Edwards et al., 1976). Supernatants were prepared and stored as above.

\section{Preparation of sperm extracts}

Spermatozoa were obtained from the caput (regions 1 to 4) and cauda (regions 8 and 9) of 6 boar epididymides by small incisions in the epididymal duct (Table 2). Spermatozoa were removed as above from 9 regions of two epididymides among the 6 under study (Fig. 2). Spermatozoa were resuspended in $0.5 \mathrm{ml} \mathrm{KRB}$, and centrifuged at $1500 \mathrm{~g}$ for $15 \mathrm{~min}$ over $4 \mathrm{ml} \mathrm{KRB}$ solution containing $30 \%$ Percoll. Sperm pellets were resuspended in $0.5 \mathrm{ml} \mathrm{KRB}$ containing $0.2 \%$ Triton X-100 (Sigma) to permeabilize the sperm membrane for the assay of carnitine and acetylcarnitine as described by Bøhmer et al. (1974). Samples were stored until use at $-20^{\circ} \mathrm{C}$. Spermatozoa were counted by the conventional haemocytometer technique.

\section{Sperm motility analysis}

The motility of spermatozoa from each of the 9 epididymal regions from 8 boar epididymides was assessed by phase-contrast microscopy on a $20 \mu \mathrm{l}$ sample on a glass slide (suspension thickness $28 \mu \mathrm{m}$ ), 10 microscopic fields being observed. Spermatozoa were classified as immotile, not progressively motile or progressively motile. The second category included all spermatozoa showing any kind of flagellar or head movement but no forward motility.

\section{Biochemical determinations}

Analysis of carnitine and acetylcarnitine. Before assay, epididymal and rete testis fluid samples were boiled for $3 \mathrm{~min}$. Samples were then centrifuged at $14000 \mathrm{~g}$ for $10 \mathrm{~min}$. The sperm suspensions were homogenized then deproteinized by centrifugation on a molecular filtration cone (CF $50 \mathrm{~A}$, Amicon) $\left(1000 \mathrm{~g}, 20 \mathrm{~min},+4^{\circ} \mathrm{C}\right)$.

Free $\mathrm{L}(-)$-carnitine determinations on the epididymal supernatants and on the sperm extract filtrates were made by the spectrophotometric method of Marquis \& Fritz (1964) as modified by Soufir et al. (1981). Briefly, assay tubes contained Hepes buffer at $160 \mathrm{mmol} / 1(\mathrm{pH} 7 \cdot 8), 0.16 \mathrm{mmol}$ acetyl CoA/l, $0.32 \mathrm{mmol}$ DTNB (5-5' dithiobis-2 nitrobenzoic acid) $/ 1,0.010 \mathrm{ml}$ of a suspension of $400000 \mathrm{U}$ carnitine acetyltransferase (CAT; EC 2.3.1.7)/1 and $0.020 \mathrm{ml}$ of the studied samples. The reaction was carried out for $30 \mathrm{~min}$. Changes in absorbance were read at $405 \mathrm{~nm}$. The value for the molar absorption coefficient used for DTNB was $13.3 \times 10^{3} \mathrm{M}^{-1} \mathrm{~cm}^{-1}$ (Biochemica Information, 1973). Measurements on a standard solution as well as on a blank solution were run with each assay.

$\mathrm{L}(-)$-Acetylcarnitine determinations. These were made by the spectrophotometric method of Marquis \& Fritz (1965a) and Pearson et al. (1974). Briefly, assay tubes contained $140 \mathrm{mmol}$ Hepes buffer (pH 7.8)/1, 0.15 mmol coenzyme $\mathrm{A} / 1,2.7 \mathrm{mmol} \mathrm{NAD} / 1,14 \mathrm{mmol}$ potassium malate $/ 1,1.7 \mathrm{mmol}$ EDTA $/ 1,0.030 \mathrm{ml}$ of the studied samples, $0.005 \mathrm{ml}$ of a suspension of malate dehydrogenase (EC 1.1.1.37) at $6 \times 10^{6} \mathrm{U} / 1,0.005 \mathrm{ml}$ of a suspension of citrate synthase (EC 4.1.3.7) at $1 \cdot 1 \times 10^{6} \mathrm{U} / 1$, and $0.005 \mathrm{ml}$ of a suspension of carnitine acetyltransferase (EC 2.3.1.7) at $400 \times 10^{3} \mathrm{U} / 1$. Changes in absorbance were read at $334 \mathrm{~nm}$. The value for the molar absorption coefficient used for NADH was $6.18 \times 10^{3} \mathrm{M}^{-1} \mathrm{~cm}^{-1}$. Results for carnitine and acetyl carnitine concentrations have been expressed per millilitre in Table 1. However, the epididymal fluid collected was diluted by the solution used to flush each region and so each epididymal fluid sample was analysed for protein concentration (Lowry et al., 1951) and results have been presented per mg protein in Fig. 1.

\section{Materials}

DTNB was from Calbiochem, San Diego, CA, U.S.A.; acetyl-CoA, CoA, carnitine acetyltransferase, malate dehydrogenase and citrate synthase were from Boehringer Mannheim, West Germany; L(-)-carnitine hydrochloride 
and $\mathrm{L}(-)$-acetylcarnitine-hydrochloride suspensions were from Sigma Chemical Co., St Louis, MO, U.S.A.; membrane filter cones (Cf 50A) and conical supports (CST 1) were from Amicon Corp, Lexington, MA, U.S.A.

\section{Results}

The distributions of free carnitine and acetylcarnitine in the fluid from the rete testis and from the different regions of the epididymis are shown in Fig. 1. The carnitine concentration remained low in the rete testis and proximal caput epididymal fluids ( $<16 \mathrm{nmol} / \mathrm{mg}$ protein). It began to increase in the distal caput $(20 \mathrm{nmol} / \mathrm{mg}$ protein in region 3$)$ then reached $200 \mathrm{nmol} / \mathrm{mg}$ protein in region 5 and

Table 1. Epididymal regions, epididymal transit time of spermatozoa, protein and carnitine concentrations in the fluid of the boar

\begin{tabular}{|c|c|c|c|c|c|c|c|c|c|c|}
\hline \multirow[b]{2}{*}{ Regions } & \multicolumn{4}{|c|}{ Caput } & \multicolumn{3}{|c|}{ Corpus } & \multicolumn{3}{|c|}{ Cauda } \\
\hline & I & 2 & 3 & 4 & 5 & 6 & 7 & 8 & 9 & \\
\hline $\begin{array}{l}\text { Duration of transit* } \\
\text { Carnitine } \\
\quad(\mu \mathrm{mol} / \mathrm{ml}) \dagger\end{array}$ & $\begin{array}{r}0.11 \\
\pm 0.05\end{array}$ & $\begin{array}{r}\mathrm{Da} \\
0.07 \\
\pm 0.03\end{array}$ & $\begin{array}{r}1-6 \\
0 \cdot 18 \\
\pm 0 \cdot 06\end{array}$ & $\begin{array}{r}0.81 \\
\pm 0.33\end{array}$ & $\begin{array}{r}1.40 \\
\pm 0.31\end{array}$ & $\begin{array}{r}\text { ys 6-8 } \\
2.38 \\
\pm 0.42\end{array}$ & & \multicolumn{3}{|c|}{$\begin{array}{c}\text { Days } 8-14 \\
14.49 \\
\pm 1.24\end{array}$} \\
\hline $\begin{array}{l}\text { Regions } \\
\text { Protein }(\mathrm{mg} / \mathrm{ml}) \S\end{array}$ & $\begin{array}{l}\mathbf{P} \\
3 \cdot 0\end{array}$ & & & $\underset{32 \cdot 0}{\mathrm{D}}$ & $\underset{64 \cdot 6}{P}$ & $\underset{50 \cdot 0}{M}$ & $\begin{array}{c}D \\
41 \cdot 0\end{array}$ & $\underset{31 \cdot 6}{P}$ & $\begin{array}{l}\mathrm{M} \\
33 \cdot 3\end{array}$ & $\begin{array}{c}\mathrm{D} \\
28 \cdot 8\end{array}$ \\
\hline
\end{tabular}

*As indicated by Singh (1962).

$\dagger$ Values are mean \pm s.e.m. for the experiments.

†: proximal, M: median, D: distal.

$\S$ Data from Schellpfeffer \& Hunter (1976).

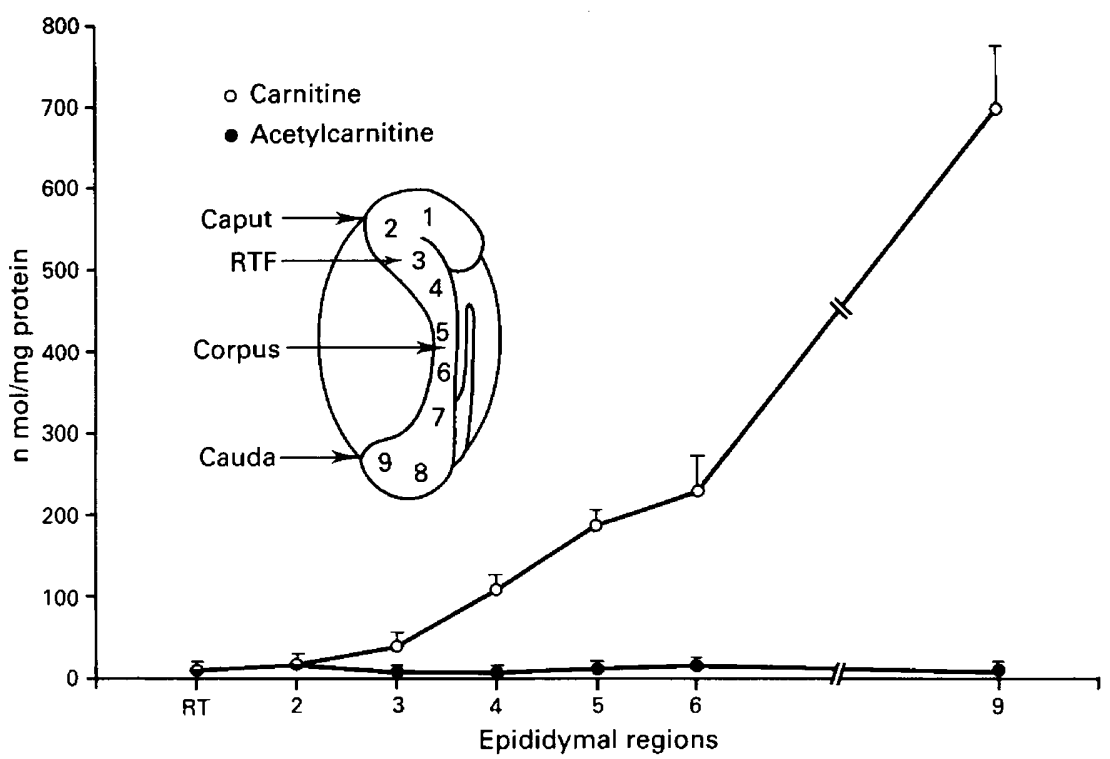

Fig. 1. L-Carnitine and L-acetylcarnitine concentrations in rete testis fluid (RTF) and in 6 of the 9 areas of epididymal fluid collection (see diagram). Each point represents the mean \pm s.e.m. of 2 values for rete testis fluid and of 6 values for epididymal samples. 
Table 2. L-Carnitine and L-acetylcarnitine contents of boar spermatozoa ( $\mathrm{nmol} / 10^{8}$ cells) removed from the caput and cauda epididymidis

\begin{tabular}{lccc}
\hline Region & Carnitine & Acetylcarnitine & Acetylated (\%) \\
\hline Caput (regions 1 to 4) & $7 \cdot 4 \pm 1 \cdot 4$ & $12 \cdot 2 \pm 3.2$ & 62 \\
Cauda (regions 8 and 9) & $51 \cdot 4 \pm 4 \cdot 0^{*}$ & $57.0 \pm 13.0^{*}$ & $52 \cdot 5$ \\
\hline
\end{tabular}

Values are mean \pm s.e.m. from 6 epididymides.

${ }^{*} P<0.01$ compared to caput value (Kruskall-Wallis non-parametric test).

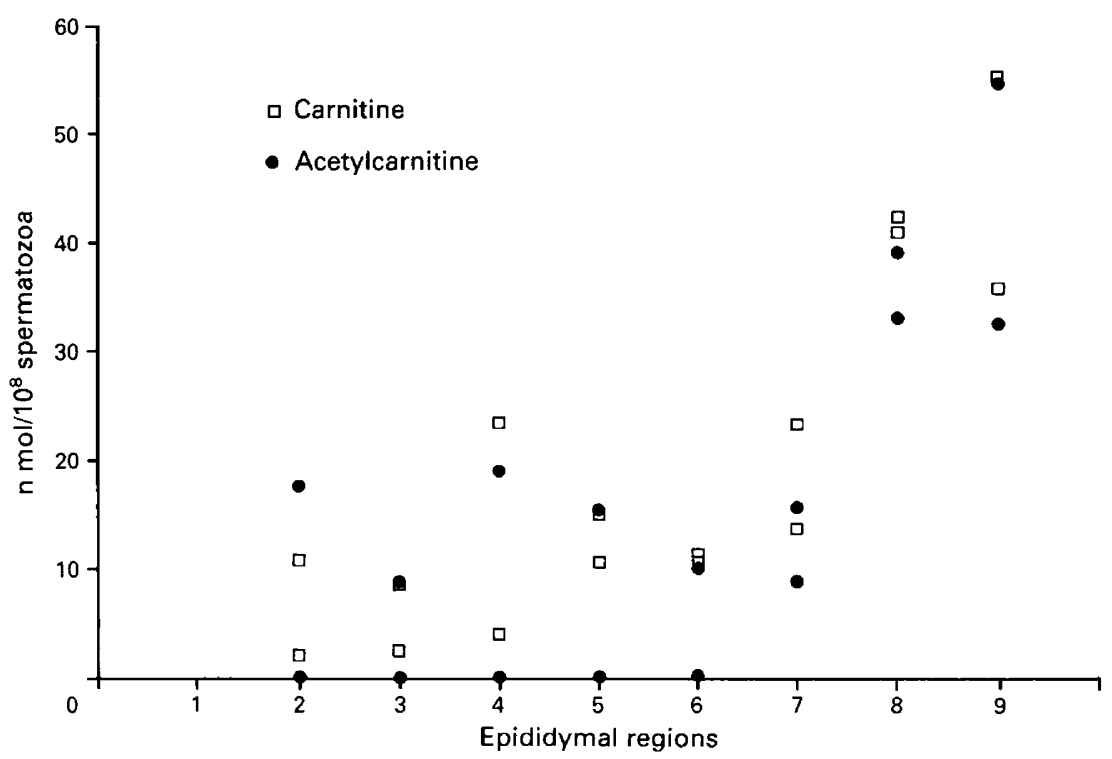

Fig. 2. L-Carnitine and L-acetylcarnitine contents of spermatozoa removed from 9 areas of 2 epididymides.

attained maximal values in the cauda $(14.5 \pm 1.2 \mu \mathrm{mol} / \mathrm{ml} ; 700 \mathrm{nmol} / \mathrm{mg}$ protein $)$. By contrast, the concentration of acetylcarnitine remained low $(7-15 \mathrm{nmol} / \mathrm{mg}$ protein) in all the epididymal regions.

The carnitine and acetylcarnitine contents of spermatozoa removed from the caput and the cauda are presented in Table 2. The levels of both compounds increased along the epididymis. As shown in Fig. 2, the carnitine and acetylcarnitine contents of spermatozoa were constantly low (about $7-10 \mathrm{nmol} / 10^{8}$ spermatozoa) from region 2 to region 6 . A significant 5-fold increase was then observed from region 7 to the distal cauda. The acetylcarnitine/carnitine ratio was constant during the whole epididymal transit of spermatozoa. The acetylcarnitine content increased in parallel with carnitine content and represented $50 \%$ of the total carnitine content (carnitine + acetylcarnitine).

The results on sperm motility are shown in Fig. 3. The percentage of motile (progressive and non-progressive) spermatozoa began to increase when the gametes reached region 2 , then gradually increased to the caudal region. By contrast, the percentage of progressively motile spermatozoa was low in regions $2-6$, and then rose abruptly from region 6 to the cauda. 


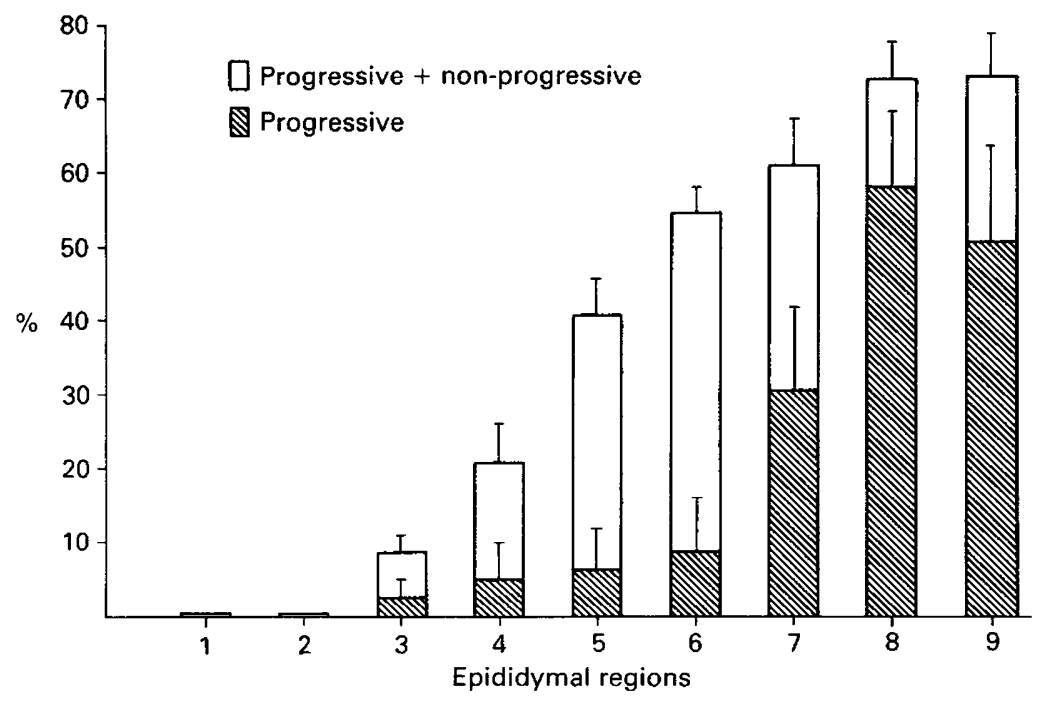

Fig. 3. Percentage of motile spermatozoa examined by phase-contrast microscopy in the 9 epididymal regions. Each point represents the mean \pm s.e.m. of 8 values.

\section{Discussion}

These results revealed that there was a time-lag between the increase in the carnitine levels of epididymal fluid and the increase in the carnitine content of epididymal spermatozoa. Indeed, whereas the carnitine levels began to increase in the fluid in the distal caput epididymidis (regions 3-4), the carnitine content of spermatozoa did not rise until the cells had reached the distal corpus (regions 6-7). An increase in the carnitine amount of the epididymal fluid has already been demonstrated in different species (Hinton et al., 1979; Besançon et al., 1985). Our results relative to the caudal epididymal fluid of the boar as expressed in $\mu \mathrm{mol} / \mathrm{ml}$ (Table 1) are similar to those obtained by Hinton et al. (1979) for the same region (15-20 mM), although we found a higher carnitine concentration gradient. However, our findings clearly indicate that the region where the carnitine begins to accumulate is the distal caput epididymidis. The acetylcarnitine amount was very low whatever the region of the epididymis considered. The carnitine acylation state of the epididymal fluid from other species (Casillas \& Chaipayungpan, 1979; Casillas et al., 1984; Brooks et al., 1974) is greater than that reported here. However, only the acetylcarnitine was estimated in our study, and the fluid sampling technique used prevented all leakage from epithelial cells.

Our results on the carnitine content of boar epididymal spermatozoa confirm previous observations that carnitine accumulates in spermatozoa as they progress along the epididymis (Casillas, 1973; Casillas \& Chaipayungpan, 1979; Casillas et al., 1984). In our study, the carnitine content of spermatozoa removed from the boar caput epididymidis was $15-20 \%$ of that of cauda spermatozoa. Variations of the same order have been observed in other species. Like carnitine, the acetylcarnitine content of spermatozoa increased during epididymal transit. The value of the acetylcarnitine: carnitine ratio did not change throughout sperm maturation and was slightly lower in boar epididymal spermatozoa $(52.5-62 \%)$ than in human and ram ejaculated spermatozoa (87 and $67 \%$ respectively) (Brooks, 1979). The fact that the increase in acetylcarnitine and carnitine followed a parallel course (regions 7-8) reveals that the carnitine acetyltransferase is already functional in immature boar spermatozoa. This belief is supported by the findings of Vernon et al. (1971) who detected activity of this enzyme in diplotene primary spermatocytes. 
Our observation that carnitine accumulates in the boar epididymal fluid sooner than in the spermatozoa suggests that the sperm membrane is not perhaps as permeable to carnitine as generally accepted (Casillas, 1973; Brooks, 1979). If we assume that the water space of epididymal spermatozoa has the same volume (about $2 \cdot 5 \mu \mathrm{l} / 10^{8}$ spermatozoa) in the boar as in man (Ford $\&$ Harrison, 1983) and the ram (Hammerstedt et al., 1979), it is possible to calculate the carnitine intracellular concentration of cauda epididymal spermatozoa from their carnitine content. This was estimated at $20-25 \mu \mathrm{mol} / \mathrm{ml}$ and is therefore not far from the value found for the carnitine concentration in the cauda epididymal fluid (Table 1). The concentration of carnitine in cauda epididymal spermatozoa is therefore very similar outside and inside the cells and the intracellular concentration of acetylcarnitine is much higher than its extracellular concentration. Acetylcarnitine is not released by caudal spermatozoa in the fluid. This high carnitine intracellular concentration probably explains why exogenous carnitine cannot penetrate the cauda epididymal spermatozoa as shown by Casillas (1973) for the bull. The question is raised whether the sperm membrane modifications that occur as the spermatozoa pass through the epididymis until regions 6-7 would prevent passive diffusion of carnitine through the membrane. The equilibrium between the inside and the outside of the spermatozoon would depend on the low rate of carnitine uptake by the cell (Casillas, 1973) and may be reached only after several hours corresponding to the duration of the transit in the corpus. However, the exact mechanism of carnitine penetration in spermatozoa during maturation is unknown.

Carnitine accumulation in epididymal spermatozoa has already been related to sperm motility by Hinton et al. (1981). Our results have shown that an increase in the percentage of progressive spermatozoa was always associated with high concentrations of carnitine and acetylcarnitine in spermatozoa. However, the increase in the percentage of motile cells in the caput region was not accompanied by intracellular carnitine changes. These observations suggest that carnitine may not be directly involved in the initiation of sperm motility. Nevertheless, its accumulation in epididymal spermatozoa may be an important factor in the acquisition of progressive motility. The carnitine acetylation may contribute to stimulate the metabolic activity of epididymal spermatozoa related to modifications in the flagellar motility. One possible clinical application may consist in measuring the acetylcarnitine content of human seminal spermatozoa for determination of the degree of epididymal maturation.

We thank Dr W. C. L. Ford for the critical discussion and Mrs F. Siryani for the English translation. This research was supported by a grant from the Institut National de la Recherche Médicale (I.N.S.E.R.M.), contract No. 135,007.

\section{References}

Besançon, J., Dacheux, J.L., Paquin, R. \& Tremblay, R.R. (1985) Major contribution of epididymis to $\alpha$-glucosidase content of ram seminal plasma. Biol. Reprod. 33, 296-301.

Biochemica Information I (1973): p. 11, Boehringer, Mannheim, GMBH.

Bohmer, T., Rydning, A. \& Solberg, H.E. (1974) Carnitine in human plasma in health and disease. Clin. Chim. Acta 57, 55-57.

Brooks, D.E. (1979) Carnitine, acetylcarnitine and the activity of carnitine acyltransferases in seminal plasma and spermatozoa of men, rams and rats. $J$. Reprod. Fert. 56, 667-673.

Brooks, D.E. (1980) Carnitine in the male reproductive tract and its relation to the metabolism of the epididymis and spermatozoa. In Carnitine Biosynthesis,
Metabolism and Functions, pp. 219-235. Eds R. A. Frenkel \& J. D. McGarry. Academic Press, New York.

Brooks, D.E., Hamilton, D.W. \& Mallek, A.H. (1974) Carnitine and glyceryl phosphorylcholine in the reproductive tract of the male rat. J. Reprod. Fert. 36, 141-160.

Casillas, E.R. (1972) The distribution of carnitine in male reproductive tissues and its effect on palmitate oxydation by spermatozoal particles. Biochim. Biophys. Acta 280, 545-551.

Casillas, E.R. (1973) Accumulation of carnitine by bovine spermatozoa during maturation in the epididymis. $J$. biol. Chem. 248, 8227-8232.

Casillas, E.R. \& Chaipayungpan, S. (1979) The distribution of carnitine and acetylcarnitine in the rabbit 
epididymis and the carnitine content of rabbit spermatozoa during maturation. J. Reprod. Fert. 56, 439-444.

Casillas, E.R. \& Erickson, B.J. (1975) The role of carnitine in spermatozoan metabolism: substrate-induced elevations in the acetylation state of carnitine and coenzyme-A in bovine and monkey spermatozoa. Biol. Reprod. 12, 275-283.

Casillas, E.R., Villalobos, P. \& Gonzales, R. (1984) Distribution of carnitine and acylcarnitine in the hamster epididymis and in epididymal spermatozoa during maturation. J. Reprod. Fert. 72, 197-201.

Dacheux, J.L. (1980) An in vitro luminal perfusion technique to study epididymal secretion. IRCS Med. Sci. 8, 137 .

Edwards, E.M., Dacheux, J.L. \& Waites, G.M.H. (1976) Effects of $\alpha$-chlorohydrin on the metabolism of testicular and epididymal spermatozoa of ram. J. Reprod. Fert. 48, 265-270.

Ford, W.C.L. \& Harrison, A. (1983) D-[1-14C]Mannitol and $\left[\mathrm{U}-{ }^{14} \mathrm{C}\right]$ sucrose as extracellular space markers for human spermatozoa and the uptake of 2-deoxyglucose. J. Reprod. Fert. 69, 479-487.

Hammerstedt, R.H., Keith, A.D., Hay, S., Deluca, N. \& Amann, R.P. (1979) Changes in ram sperm membranes during epididymal transit. Archs Biochem. Biophys. 196, $7-12$.

Hinton, B.T., Snoswell, A.M. \& Setchell, B.P. (1979) The concentration of carnitine in the luminal fluid of the testis and epididymis of the rat and some other mammals. J. Reprod. Fert. 56, 105-111.

Hinton, B.T., Brooks, D.E., Dott, H.M. \& Setchell, B.P. (1981) Effects of carnitine and some related compounds on the motility of rat spermatozoa from the caput epididymis. J. Reprod. Fert. 61, 59-64.

Imai, H., Niwna, K. \& Iritani, A. (1979) Time requirement of capacitation of boar spermatozoa assessed by their ability to penetrate the zona-free hamster egg. J. Reprod. Fert. 56, 489-492.

Inskeep, P.B. \& Hammerstedt, R.H. (1982) Changes in metabolism of ram sperm associated with epididymal transit or induced by exogenous carnitine. Biol. Reprod. 27, 735-743.

Lowry, O.H., Rosebrough, M.T., Farr, A.L. \& Randall, R.J. (1951) Protein measurement with the Folin phenol reagent. J. biol. Chem. 193, 265-275.
Marquis, N.R.P. \& Fritz, I.B. (1964) Enzymological determination of free carnitine concentrations in rat tissues. J. Lipid Res. 5, 184-187.

Marquis, N.R.P. \& Fritz, I.B. (1965a) The distribution of carnitine acetylcarnitine and carnitine acetyl transferase in rat tissues. J. biol. Chem. 240, 2193-2197.

Marquis, N.R.P. \& Fritz, I.B. (1965b) Effects of testosterone on the distribution of carnitine, acetylcarnitine and carnitine acetyltransferase in tissues of the reproductive system of the male rat. J. biol. Chem. 240, 2197-2200.

Milkowski, A.L., Babcock, D.F. \& Lardy, H.A. (1976) Activation of bovine epididymal sperm respiration by caffeine, its transient nature and relationship to the utilization of acetylcarnitine. Archs Biochem. Biophys. 176, 250-256.

Pearson, D.J., Tubbs, P.K. \& Chase, F.A. (1974) Carnitine and acylcarnitines. In Methods of Enzymatic Analysis, pp. 1758-1771. Ed. H. U. Bergmeyer. Verlag Chemie, Weinheim.

Schellpfeffer, A. \& Hunter, A.G. (1976) Specific protein of the male reproductive tract. In Regulatory Mechanism of Male Reproductive Physiology, pp. 115-128. Eds C. H. Spilman, T. J. Lobl, K. T. Kirton. Excerpta Medica, Amsterdam.

Singh, G. (1962) Durée de passage dans l'épididyme des spermatozoïdes de verrat marqués au ${ }^{32} \mathbf{P}$. Annls Biol. anim. Biochim. Biophys. 2, 43-46.

Soufir, J.C. \& Jeulin C. (1985) Origin of L-acetyl carnitine of human seminal plasma. Prog. Reprod. Biol. Med. 12, 99-103.

Soufir, J.C., Marson, J. \& Jouannet, P. (1981) Free (L) carnitine in human seminal plasma. Int. J. Androl. 4, 388-393.

Van Dop, C., Huston, S.M. \& Lardy, H.A. (1977) Pyruvate metabolism in bovine epididymal spermatozoa. J. biol. Chem. 252, 1303-1308.

Vernon, R.G., Go, V.L.W. \& Fritz, I.B. (1971) Studies on spermatogenesis in rats. II Evidence that acetyl carnitine transferase is a marker enzyme for the investigation of germ cell differentiation. Can. J. Biochem. 49, 761--767. 